\title{
Don't forget chronic lung and immune conditions during covid-19, says WHO
}

\author{
Jacqui Thornton
}

London, UK

The World Health Organization has called on the global community to continue efforts to tackle longstanding health problems during outbreaks like covid-19 as it published new guidance on tuberculosis (TB) prevention.

Speaking on world TB day, WHO director general Tedros Adhanom Ghebreyesus said covid-19 highlighted just how vulnerable people with lung diseases and weakened immune systems can be.

But he said that programmes already in place to combat TB and other major infectious diseases can be leveraged to make the response to covid-19 more effective and rapid.

The new consolidated WHO guidance recommends scaling up TB preventive treatment among populations at highest risk, including household contacts of TB patients, people living with $\mathrm{HIV}$, and other people at risk with lowered immunity or living in crowded settings.

It also recommends an integration of $\mathrm{TB}$ preventive treatment services into ongoing case finding efforts for active TB and shorter, safer options for preventive treatment in addition to the widely used six months of daily isoniazid.

The new guidelines come with an operational handbook to help guide countries and a mobile app customised by country to allow programme managers to visualise and monitor data in real time. It is currently being adopted in India and the Philippines.

Paula Fujiwara, scientific director of the International Union Against Tuberculosis and Lung Disease (the Union), said that by preventing TB in the first place, a possible risk factor for covid-19 is removed.

She added, "A person with TB often ends up with post-TB lung disease which can diminish the ability to respond to a novel organism that has respiratory effects.
"Prevention can encompass covid-19. Prevention is the biggest tool we have to tackle it and we must do all we can, as we have no treatment, no vaccine, and only supportive care, which is not good enough for many of the infected."

TB remains the world's top infectious killer, with 10 million people falling ill worldwide and 1.5 million people losing their lives to the disease in 2018. ${ }^{1}$ A quarter of the world's population is estimated to be infected with TB bacteria and at risk of developing the disease.

Some progress has been made towards the targets set at the UN high level meeting on TB in 2018 where global leaders committed to ensuring access to TB preventive treatment to at least 24 million contacts of people with active TB and 6 million people living with HIV by $2022 .^{2}$ Only a fraction of that target has been reached, however, with countries putting less than 430 000 contacts and 1.8 million people on TB preventive treatment in $2018 .^{3}$

The Union called for an emphasis on prevention at its conference last year. ${ }^{4}$ Fujiwara said that prevention required political will. "In the case of TB, there are drugs available to implement prevention on a grand scale, but as WHO figures indicate, rolling out preventative therapy to those who need it is still too slow."

WHO. Tuberculosis. www who.int/news-room/fact-sheets/detail/tuberculosis.

2 WHO. Political declaration of the UN general assembly high-level meeting. 2018. www. who.int/tb/unhlmonTBDeclaration.pdf.

3 WHO Global Tuberculosis Report 2019. 2019. www.who.int/tb/publications/global_report/ en/

4 Thornton J. An ounce of tuberculosis prevention.... Lancet Infect Dis 2019;19:1291-2. 10.1016/S1473-3099(19)30645-0 31782399

Published by the BMJ Publishing Group Limited. For permission to use (where not already granted under a licence) please go to http://group.bmj.com/group/rights-licensing/ permissions 